\title{
Mrs Carolyn Ann Gilchrist, Editorial Secretary
}

In 1993 I was fortunate in obtaining the services of Carolyn Gilchrist as the editorial secretary of Spinal Cord. She had important secretarial experiences in a number of hospitals in several medical spheres including, in London, Radiotherapy, University College; Neurology and General Surgery, St Marys and Histopathology, Royal Free.

She then came to Edinburgh and worked initially in an adult General Surgical Unit and then moved to the Royal Hospital for Sick Children where she was medical secretary in Cardiology and in 1990 joined the Paediatric Neurology and Neurosurgery Department.

Thus, she had an excellent medical secretarial background and, as I expected and indeed found, a most pleasant personality. Very soon Carolyn 'learned the ropes' of the demanding and varied requirements of being editorial secretary for an international medical scientific journal, necessitating close communications and coordination with authors, reviewers, our publishers and with libraries. I thank her very much indeed for her loyal, exceptionally hard work.

With the journal office now moving down to Southampton in England with the new editor, Dr Illis, I require to say au revoir to Carolyn and I take this opportunity of wishing her and Ian, her husband, a happy Silver Wedding Anniversary in November and continued success in her work in the future.

Phillip Harris Editor, Spinal Cord

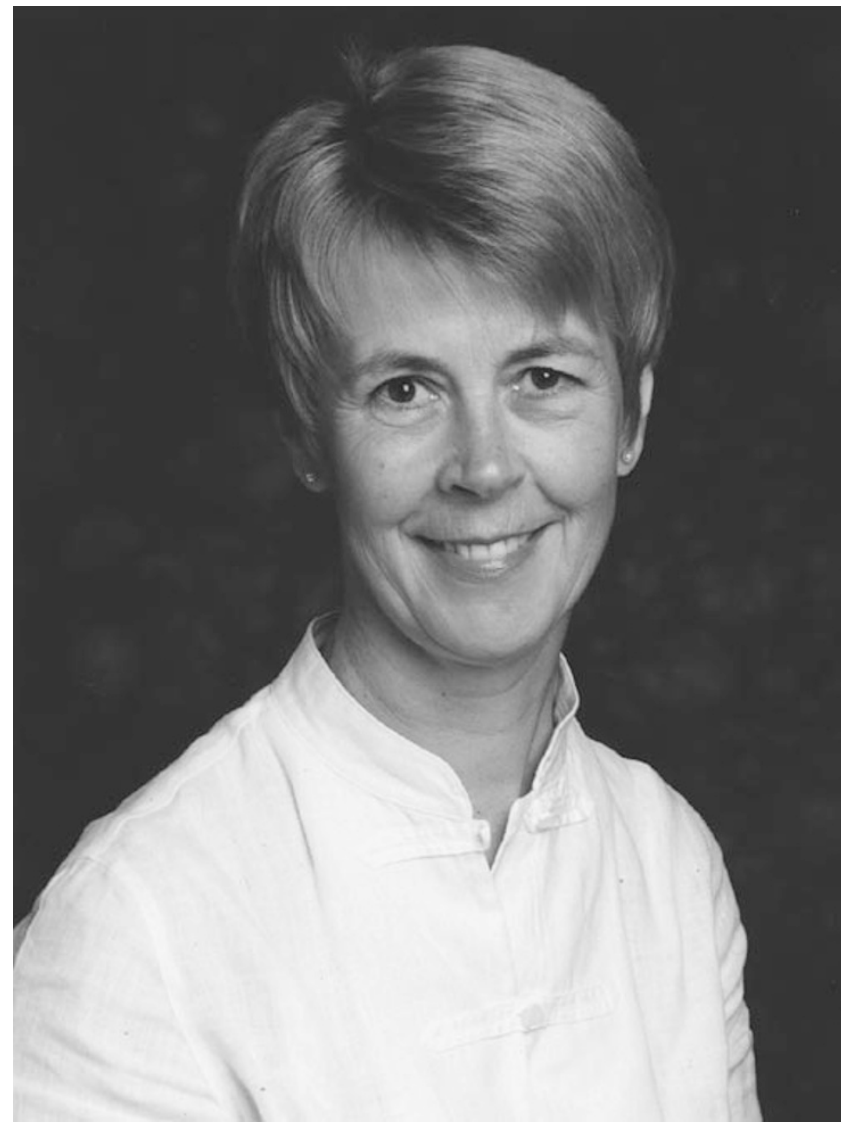

